\title{
REVERSES OF THE TRIANGLE INEQUALITY IN INNER PRODUCT SPACES
}

\section{Lingling Zhang, Tomoyoshi OHwadA And Muneo ChO}

Abstract. We show that if $x_{1}, \cdots, x_{n}$ are vectors in a normed linear space $(X,\|\cdot\|)$ and $s_{1}, \cdots, s_{n}$ belong to the interval $[0, \infty)$, then

$$
f_{n}\left(s_{1}, \cdots, s_{n}\right)=\sum_{j=1}^{n}\left\|s_{j} x_{j}\right\|-\left\|\sum_{j=1}^{n} s_{j} x_{j}\right\|
$$

is a non-negative valued continuous function such that $f_{n}\left(s_{1}, \cdots, s_{n}\right) \leqslant f_{n}\left(t_{1}, \cdots, t_{n}\right)$ for all $s_{1}, \cdots, s_{n}$ and $t_{1}, \cdots, t_{n}$ in $[0, \infty)$ with $s_{j} \leqslant t_{j}(1 \leqslant j \leqslant n)$. By using it, we prove several versions of reverse triangle inequality in inner product spaces and discuss equality attainedness of norm inequalities in strictly convex Banach spaces.

Mathematics subject classification (2010): 46B20, 46B99, 26D15.

Keywords and phrases: triangle inequality, inner product space, strictly convex Banach space.

\section{REFERENCES}

[1] A. H. ANSARI AND M. S. Moslehian, More on reverse triangle inequality in inner products spaces, Int. J. Math. Math. Sci. (2005), no. 18, 2883-2893.

[2] F. Dadipour, M. S. Moslehian, J. M. Rassias and S.-E. Takahasi, Characterization of a generalized triangle inequality in normed spaces, Nonlinear Anal. 75 no. 2 (2012), 735-741.

[3] S. S. DRAGOMIR, Reverses of the triangle inequality in inner product spaces, Aust. J. Math. Anal. Appl. 1 no. 2 (2004), 1-14.

[4] S. S. DrAGOMIR, Reverses of the triangle inequality in Banach spaces, JIPAM. J. Inequal. Pure Appl. Math. 6(5) (2005), Art. 129, pp. 46.

[5] M. Fujil, M. Kato, K.-S. Saito And T. TAmura, Sharp mean triangle inequality, Math. Inequal. Appl. 13 (2010), 743-752.

[6] C.-Y. Hsu, S.-Y. Shaw AND H.-J. Wong, Refinements of generalized triangle inequalities, J. Math. Anal. Appl. 344 (2008), 17-31.

[7] M. Khosravi, H. Mahyar and M. S. Moslehian, Reverse triangle inequality in Hilbert C*modules, JIPAM. J. Inequal. Pure Appl. Math. 10 no. 4 (2009), Article 110, 11 pp.

[8] M. KATO, K.-S. SAITO AND T. TAMURA, Sharp triangle Inequality and its reverse in Banach spaces, Math. Inequal. Appl. 10 no. 2 (2007), 451-460.

[9] L. MaligrandA, Some remarks on the triangle inequality for norms, Banach J. Math. Anal. 2 no. 2 (2008), 31-41.

[10] M. S. Martirosyan And S. V. SAmarchyan, Inversion of the triangle inequality in $\mathbb{R}^{n}, \mathbf{3 8}$ (2003), no. 4, 65-72.

[11] K. Mineno, Y. Nakamura And T. Ohwada, Characterization of the intermediate values of the triangle inequality, to appear in Math. Ineq. Appl.

[12] K. Mineno, Y. Nakamura, S. Nakamura, C. Tamiya and T. Ohwada, Characterization of the intermediate values of the triangle inequality II, in preparation.

[13] K.-I. Mitani, K.-S. Saito, M. Kato AND T. TAmura, On sharp triangle Inequalities in Banach spaces, J. Math. Anal. Appl. 10 no. 2 (2007), 451-460. 
[14] K.-I. Mitani, K.-S. SAito, On sharp triangle Inequalities in Banach spaces II, J. Inequal. Appl. (2010), Art. ID 323609, 17 pp.

[15] S. S AIтоH, Generalizations of the triangle inequality, JIPAM. J. Inequal. Pure Appl. Math. 4 (2003), no. 3, Article 62, 5 pp. 